\title{
Experimental Testing and Theoretical Prediction of Fiber Optical Cable for Fault Detection and Identification
}

\author{
${ }^{1}$ H. J. Abbas, ${ }^{2}$ M.J. Jweeg, ${ }^{3}$ Muhannad Al-Waily and ${ }^{4}$ Abbas Ali Diwan \\ ${ }^{1}$ Telafer University Mosul, Mosul, Iraq \\ ${ }^{2}$ Department of Scientific Affairs, Telafer University Mosul, Mosul, Iraq \\ ${ }^{3}$ Department of Mechanical Engineering, Faculty of Engineering, \\ ${ }^{4}$ Nanotechnology and Advance Material Research Unit, University of Kufa, Kufa, Iraq
}

\begin{abstract}
Optical fiber cable suffers from some fault such as bending, crack and break which deteriorate the performance of the cable. The level of the signals transmitted in the cable attenuated very highly according to the faults. An experimental test has been carried on normal single mode cable. Different types of defects have been created on the same cable such as bending, crack and break. The results of the tests of the faulty and un faulty cables are compared. It is found that the spectral properties of the faulty cable are changed according to the type of the defect. The frequency spectrum of the exited cable has been changed due to the changes of the faults. The type of the fault is detected and identified according to the changes of the natural frequencies of the excited cable. The natural frequency of cable with different crack is evaluated by using experimental work and are compared with the results by using analytical solution and Artificial Neural Network (ANN) data. The results showed that the natural frequency is changed by changing the depth or position of crack, then, the crack position or its size can be determined by evaluating the natural frequency of the cable. The comparisons of the results of both techniques are showed a good agreement. The experimental and ANN data showed a maximum error $<1 \%$ and the comparison of the experimental with analytical solution is showed an error $<11.26 \%$.
\end{abstract}

Key words: Cable, defect, crack, fault, spectrum, ANN

\section{INTRODUCTION}

The crack effect in any structure is important subject in engineering, therefore, the effect of crack on the natural frequency of cable is a valuable parameter. Since, by evaluating the natural frequency with experimental or any other technique the crack occurred in the cable can be predicted. Many researchers studied the effect of crack on optical cable structure included various effects as, dynamic, static, buckling, cracks, bending and other effects.

Barnoski and Personick (1978) have demonstrated new method of loss measurement and defect detection and location. Gilgen et al. (1989) have developed optical reflectometer for fault detection and location. Glombitza and Brinkmeyer (1993) have developed coherent Frequency Domain Reflectometry OFDR to detect the faults of optical fiber cable and locate them. Abbas and Taha (2010) presented a computer simulation reflectometer for detection of the faults in the optical fiber cables. There are many other researchers dealt with mechanical structure faults detection and location. Parhi and Khan (2012) studied the fault detection of mechanical system using the change in the natural frequencies of faulty and unfaulty structures. Riveros et al. (2010) presented a numerical investigation to detect the crack and locating it using strain energy principles. They applied this technique in the beam structure. Parhi and Das (2008) employed fuzzy logic technique for detecting the crack in the structure by measuring natural frequencies of the structure .These frequencies used as input to the fuzzy interface for predicting the crack depth and location. Since, there is a big similarity between the beam structure and optical cable, there is a possibility to apply the natural frequency response analysis in this subject.

The novelty of this research is to apply theory of frequency response analysis in detection and identification of defects of mechanical structures that occur in the optical fiber cables. The spectrum analyzer which uses FFT technique is applied to determine the natural frequencies of the defected and undefected cables. The output of the FFT analyzer is applied to an artificial neural network for the detection location and

Corresponding Author: Muhannad Al-Waily, Department of Mechanical Engineering, Faculty of Engineering, University of Kufa, Kufa, Iraq 
identification of the fault in the optical fiber cables. The technique of applying the theory of natural frequency response analysis is much simpler and easier to apply for the detection location and identification of the faults in fiber optical cables especially in practical applications than using the spectrum analyzer for the analysis of the of the spectrum of the reflected signal in optical range which needs very high resolution and very high sensitive tools. Since, the reflected signals in the defected cables would be very low which needs highly sensitive equipment to detect these signals, reversely. In the natural frequency analysis technique, there is no such a problem.

A suggested analytical solution: The theory of natural frequency analysis is used is for the fault detection of the optical fiber. The analytical investigation including the effect of crack on cable is achieved by adding the effect of crack as discontinuous section occur at the crack position. In the suggested equation the area of the cable is non-uniform along the cable length. The crack is considered as a crack in a beam and has an effect on the moment of inertia in the beam vibration (Al-Waily, 2015; Al-Waily and Deli, 2016; Jweeg, 2016). Assume that the crack effect on the cable cross section is modeled as follows:

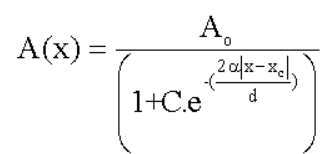

Where:

$$
\begin{array}{ll}
\mathrm{C}=\mathrm{A}_{0}-\mathrm{A}_{c} / \mathrm{A}_{c}, \mathrm{~A}_{0} & =\text { The cable area without crack } \\
\mathrm{A}_{0} & =\text { The cable area at crack section } \\
\mathrm{d} & =\text { The cable diameter } \\
\mathrm{x} & =\text { The position along the beam } \\
\mathrm{x}_{\mathrm{c}} & =\text { The crack position along the beam } \\
\alpha & =\text { The constant }
\end{array}
$$

can be using 0.667 (Al-Waily, 2015; Al-Waily and Deli, 2016). Then, the force action on cable is:

$$
\mathrm{P}(\mathrm{x})=\sigma^{*} \mathrm{~A}(\mathrm{x})=\sigma \frac{\mathrm{A}_{o}}{\left(1+\mathrm{C} \cdot \mathrm{e}^{-\left(\frac{\left.2 \alpha \mid \mathrm{x}-\mathrm{z}_{\mathrm{c}}\right)}{\mathrm{d}}\right)}\right)}
$$

where, $\sigma$ is the stress applied on the cable without crack, it is cab be evaluated by:

$$
\sigma=\mathrm{P}_{0}{ }^{*} \mathrm{~A}_{0}
$$

where, $P_{0}$ is the load applied on the cable without crack effect and can be evaluated by using experimental work, as shown in experimental work section. Then, by substation Eq. 3 into Eq. 2, gives:

$$
\mathrm{P}(\mathrm{x})=\sigma^{*} \mathrm{~A}(\mathrm{x})=\frac{\mathrm{P}_{\mathrm{o}}}{\left(1+\mathrm{C} \cdot \mathrm{e}^{-\left(\frac{2 \mathrm{o}\left|\mathrm{x}-\mathrm{x}_{\mathrm{c}}\right|}{\mathrm{d}}\right)}\right)}
$$

Therefore, the general equation of motion of cable vibration (Jweeg, 2016; Hein and Feklistova, 2011):

$$
\frac{\partial}{\partial x}\left(P(x) \frac{\partial w(x, t)}{\partial x}\right)=\rho \frac{\partial^{2} w(x, t)}{\partial t^{2}}
$$

Where:

$\rho \quad=$ Density of cable

$\mathrm{w}(\mathrm{x}, \mathrm{t})=$ The response of cable as a function of $\mathrm{x}$-direction and time in $\mathrm{z}$ direction

Thus, using Eq. 4 into 5, achieving first transformation of Eq. 4 from discontinuous equation to the continuous equation by using Fourier series technique as (Dash, 2012):

$\mathrm{P}(\mathrm{x})=\mathrm{A}_{0}+\sum_{\mathrm{n}=1}^{\infty} \mathrm{A}_{\mathrm{n}} \cos \frac{2 \pi \mathrm{n} x}{1}+\sum_{\mathrm{n}=1}^{\infty} \mathrm{B}_{\mathrm{n}} \sin \frac{2 \pi \mathrm{n} \mathrm{x}}{1}$, for, $0 \leq \mathrm{x} \leq 1$

where, $A_{0}, A_{n}, B_{n}$ are constants of Fourier series they are evaluated as follows:

$$
\begin{aligned}
& A_{0}=\frac{1}{1} \int_{0}^{1} \mathrm{P}(\mathrm{x}) \mathrm{dx} \\
& \mathrm{A}_{\mathrm{n}}=\frac{2}{1} \int_{0}^{1} \mathrm{P}(\mathrm{x}) \cos \frac{2 \pi \mathrm{nx}}{1} \mathrm{dx}=\frac{2}{1} \int_{0}^{1} \frac{\mathrm{P}_{0}}{\left(1+\mathrm{C} \cdot \mathrm{e}^{-\left(\frac{\left.2 \mathrm{a} \mid \mathrm{x}-\mathrm{x}_{\mathrm{c}}\right)}{\mathrm{d}}\right)}\right)} \cos \frac{2 \pi \mathrm{nx}}{1} \mathrm{dx} \\
& \mathrm{B}_{\mathrm{n}} \frac{2}{1} \int_{0}^{1} \mathrm{P}(\mathrm{x}) \sin \frac{2 \pi \mathrm{nx}}{1} \mathrm{dx}=\frac{2}{1} \int_{0}^{1} \frac{\mathrm{P}_{0}}{\left(1+\mathrm{C} \cdot \mathrm{e}^{-\left(\frac{\left.2 \mathrm{a} \mid \mathrm{x}-\mathrm{x}_{\mathrm{c}}\right)}{\mathrm{d}}\right)}\right)} \sin \frac{2 \pi \mathrm{nx}}{1} \mathrm{dx}
\end{aligned}
$$

Then, substation Eq. 6 into Eq. 5, gives:

$$
\begin{aligned}
& \left(\begin{array}{l}
\left(\mathrm{A}_{\mathrm{o}}+\sum_{\mathrm{n}=1}^{\infty} \mathrm{A}_{\mathrm{n}} \cos \frac{2 \pi \mathrm{n} x}{1}+\sum_{\mathrm{n}=1}^{\infty} \mathrm{B}_{\mathrm{n}} \sin \frac{2 \pi \mathrm{n} x}{1}\right) \frac{\partial^{2} \mathrm{w}(\mathrm{x}, \mathrm{t})}{\partial \mathrm{x}^{2}}+ \\
\left(\sum_{\mathrm{n}=1}^{\infty} \mathrm{B}_{\mathrm{n}}\left(\frac{2 \pi \mathrm{n}}{1}\right) \cos \frac{2 \pi n \mathrm{x}}{1}-\sum_{\mathrm{n}=1}^{\infty} \mathrm{A}_{\mathrm{n}}\left(\frac{2 \pi \mathrm{n}}{1}\right) \sin \frac{2 \pi \mathrm{x}}{1}\right) \frac{\partial \mathrm{w}(\mathrm{x}, \mathrm{t})}{\partial \mathrm{x}}
\end{array}\right)= \\
& \rho \frac{\partial^{2} w(x, t)}{\partial t^{2}}
\end{aligned}
$$

Therefore, the solution of Eq. 7, the response of cable is evaluated as a function of $\mathrm{x}$-direction by substitution the boundary condition of cable. Then, considering the effect of crack on the response of cable is very small, thus, the response of cable with crack will be the same response of 
cable without cark. Then, by using clamped supports for the cable, the response mode can be assumed as follows (Hein and Feklistova, 2011):

$$
\begin{aligned}
& \mathrm{w}(\mathrm{x})=\sin \frac{\mathrm{m} \pi \mathrm{x}}{1} \\
& \left(\begin{array}{l}
\left(\sum_{n=1}^{\infty} B_{n}\left(\frac{2 \pi n}{1}\right) \cos \frac{2 \pi n x}{1}-\sum_{n=1}^{\infty} A_{n}\left(\frac{2 \pi n}{1}\right) \sin \frac{2 \pi n x}{1}\right)\left(\frac{m \pi}{1}\right) \cos \frac{m \pi x}{1} w(t)- \\
\left(A_{0}+\sum_{n=1}^{\infty} A_{n} \cos \frac{2 \pi n x}{1}+\sum_{n=1}^{\infty} B_{n} \sin \frac{2 \pi n x}{1}\right)\left(\frac{m \pi}{1}\right)^{2} \sin \frac{m \pi x}{1} w(t)
\end{array}\right)=\rho \sin \frac{m \pi x}{1} \frac{\partial^{2} w(t)}{\partial t^{2}} \\
& w(x, t)=\sin \frac{m \pi x}{1} w(t)
\end{aligned}
$$

where, $\mathrm{m}$ is constant equal to $(1,2,3, \ldots$,$) . Therefore, the$ general response equation for cable as a function of displacement and time is:

Then, by substitution of $\mathrm{w}(\mathrm{x})$ from Eq. 9 into Eq. 7, gives:

Therefore, by using orthogonality by response mode of cable equation, Eq. 8, technique, (Al-Waily, 2015) by multiplying Eq. 10 gives:

$$
\left(\begin{array}{l}
\left(\sum_{n=1}^{\infty} B_{n}\left(\frac{2 \pi n}{1}\right) \cos \frac{2 \pi n x}{1}-\sum_{n=1}^{\infty} A_{n}\left(\frac{2 \pi n}{1}\right) \sin \frac{2 \pi n x}{1}\right)\left(\frac{m \pi}{1}\right) \frac{1}{2} \sin \frac{2 m \pi x}{1}- \\
\left(A_{0}+\sum_{n=1}^{\infty} A_{n} \cos \frac{2 \pi n x}{1}+\sum_{n=1}^{\infty} B_{n} \sin \frac{2 \pi n x}{1}\right)\left(\frac{m \pi}{1}\right)^{2} \sin ^{2} \frac{m \pi x}{1}+
\end{array}\right) w(t)=\rho \sin ^{2} \frac{m \pi x}{1} \frac{\partial^{2} w(t)}{\partial t^{2}}
$$

Finally, integrating Eq. 11 for $0 \leq x \leq 1$, the general equation of natural frequency for fixed supported cable with various crack size and location effect can be obtained.

\section{MATERIALS AND METHODS}

Experimental work: An experimental work is used to predict the crack size or position by calculating the natural frequency of the cable. The experimental work includes evaluating the mechanical properties and the natural frequency of clamped cable from two edges with different crack position and size. The cable under test a, length of $50 \mathrm{~cm}$, density $45 \mathrm{~g} / \mathrm{m}$ and diameter $7.5 \mathrm{~mm}$. Figure 1 shows the cable used in experimental work with and with-out crack.

The first step in experimental research included evaluating the mechanical properties of cable by using the universal tensile test machine, shown in Fig. 2. The tensile test includes evaluating the yield stress of the samples. The bench used for the test is shown in Fig. 3. By taking the average value of these samples, the yield stress calculated for cable is about $\sigma_{\mathrm{y}} \approx 12 \mathrm{MPa}$ as shows in Table 1.

After tensile test of the cable material, the cable is tested by a vibration test rig to evaluate the natural frequency of cable with different crack depth and various positions, supported by two fixed ends. The vibration test rig is composed from the following parts as shown in Fig. 4:

\begin{tabular}{lc} 
Table 1: Tensile test results for three cable samples & \\
\hline Sample No. & Yield stress (MPa) \\
\hline 1 & 12.0 \\
2 & 11.8 \\
3 & 12.5 \\
Average & 12.1 \\
\hline
\end{tabular}

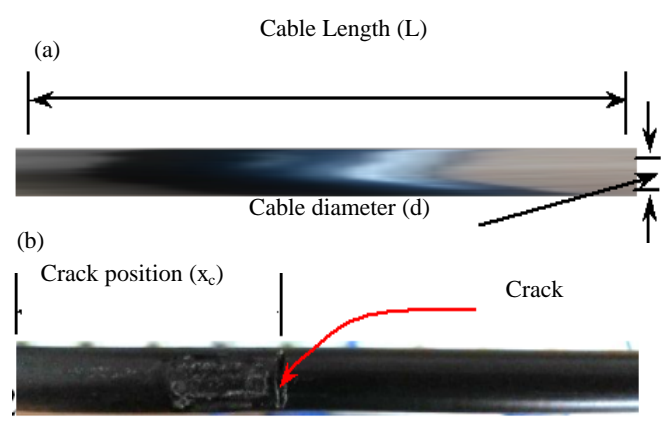

Fig. 1: Cable vibration samples; a) Cable without crack and b) Cable with crack

- Frame rig to support the cable sample and other compounds

- Cable sample under test by vibration test to evaluate the natural frequency of the cable

- Accelerometer to sense the vibration response of the cable

- Amplifiers for amplification of the response signal of vibrated cable under tests

- Oscilloscope to read the response signal from accelerometer 


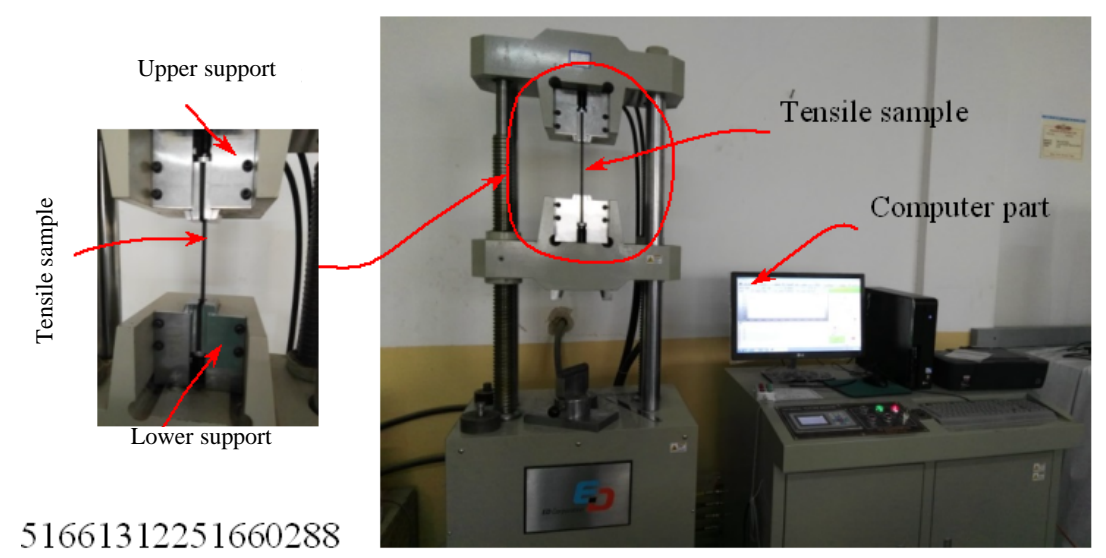

Fig. 2: Tensile test machine

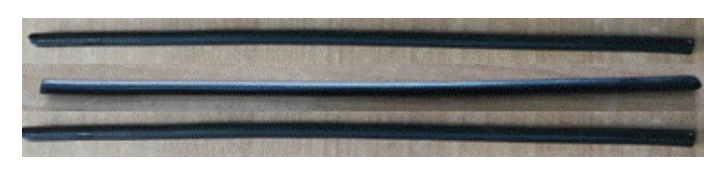

Fig. 3: Tensile samples

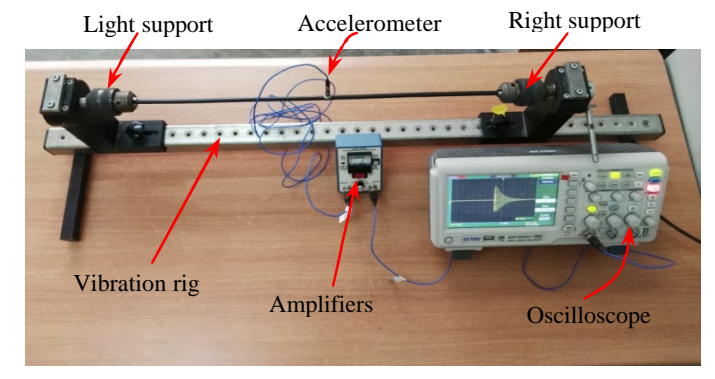

Fig. 4: Vibration rig parts

The crack depths used in the experiments are $\left(d_{c} / d=0.1,0.2, \ldots, 0.9\right)$ for various crack position $\left(x_{c} / L=0.1\right.$, $0.2, \ldots, 0.5)$ where, $d_{c}$ is crack depth and $x_{c}$ is crack position.

The response analysis of the vibrated cable is read by Oscilloscope using Fast Fourier Transformation (FFT) with sig-view program. Thus, the program transforms the signal from time domain to frequency domain and the natural frequency can be measured from the maximum amplitude of output-frequency figure, as shown in Fig. 5, (Al-Waily, 2013; Jweeg et al., 2012).

Therefore, after evaluating the natural frequency of cable can be calculate the force applied on the cable $\mathrm{P}_{0}$. Where, the applying $P_{0}$ cab be evaluated from the natural frequency of fixed cable without crack effect as (Rao, 2011):

$$
\omega=\frac{\pi}{1} \sqrt{\frac{P_{0}}{\rho}}
$$

where, $\omega$ is the natural frequency of cable without fault, it's evaluated by experimental work. Then, the $P_{0}$ can be calculated from:

$$
\mathrm{P}_{0}=\left(\frac{\omega 1}{\pi}\right)^{2} \rho
$$

Therefore, the value of $P_{0}$ is substituted in Eq. 4, to calculate the natural frequency analytically.

Application of theory of Neural Network (ANN): An Artificial Neural Network (ANN) is a model for data processing that attempts to imitate the human brain. The significant point of ANN Model is the construction of the information processing system. It includes a huge number of correlative manipulation elements (neurons) acting together solve a certain problem. Also, ANN can be utilized for studies of the properties of different materials according to experimental data. ANN can also be used to determine and identification of faults in cables (Elkordy et al., 1993).

In this research ANN used in MATLAB-R2014a. Figure $6 \mathrm{a}, \mathrm{b}$ shows a multilayer feed forward ANN. It is clear that the ANN is constructed with three basic layers: input layer, hidden layer and output layer. The hidden layer must include one or more layers according to performing behavior of ANN. The layer(s) consist of many of neural elements (nodes). Then the connections between these elements will govern the determination of the network performance.

The relationships between the input vectors $\mathrm{X}=\left[\mathrm{x}_{1}, \mathrm{x}_{2}, \mathrm{x}_{3}, \ldots, \mathrm{x}_{\mathrm{n}}\right]$ and the neuron output $(\mathrm{y})$ of network can be written as follows:

$$
\mathrm{y}=\sum_{\mathrm{i}=1}^{\mathrm{n}}\left(\mathrm{x}_{\mathrm{i}} \mathrm{w}_{\mathrm{i}}\right)+\mathrm{b}
$$


(a)
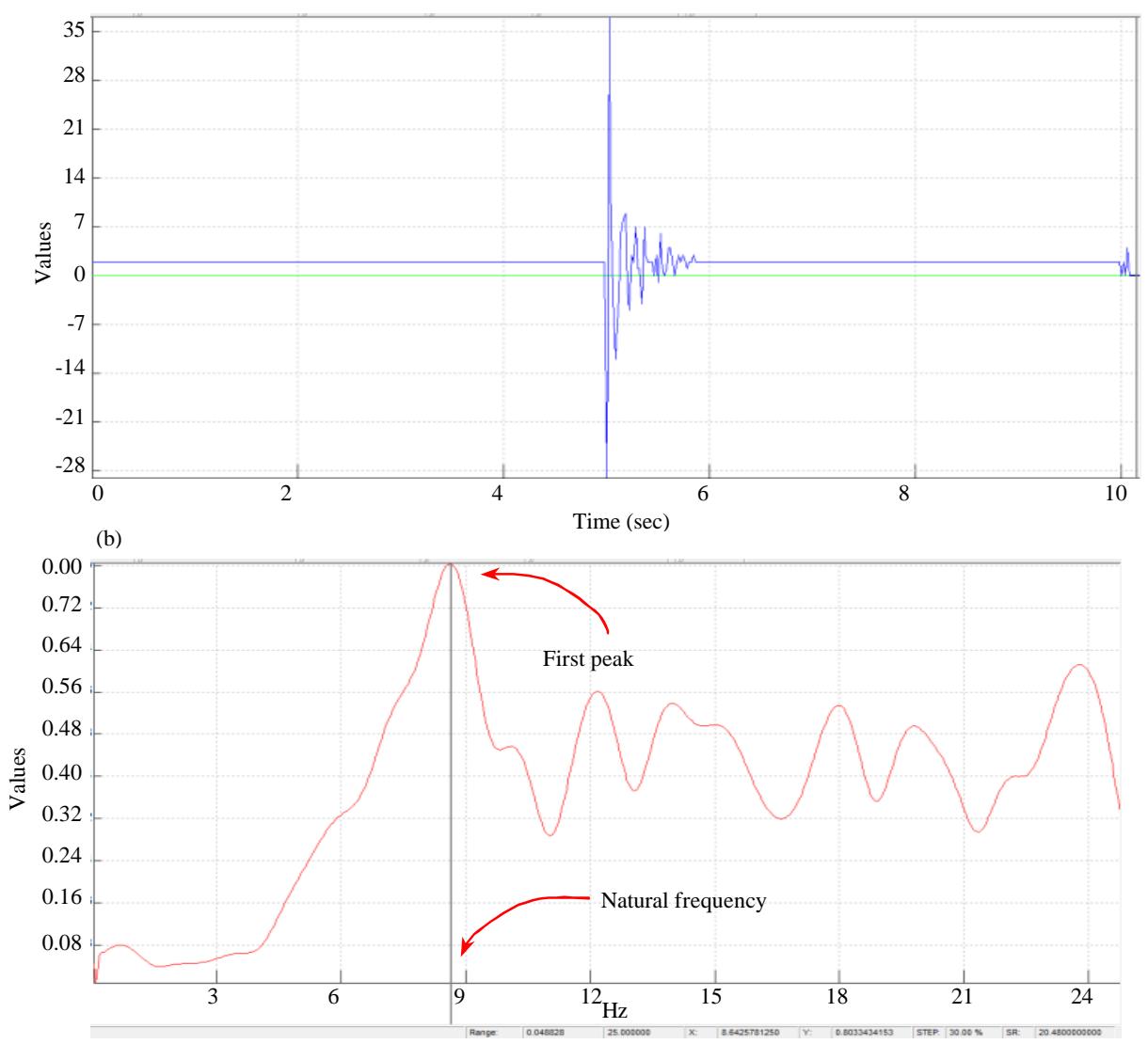

Fig. 5: Analysis of accelerometer output signal; a) Accelerometer output signal in time-domain and b) FFT output signal in frequency domain

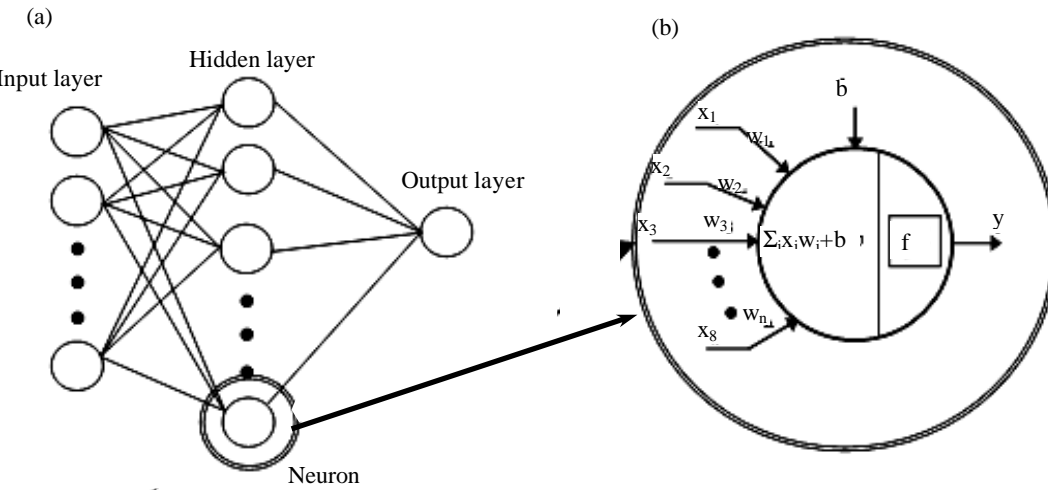

Fig. 6: Analysis of ANN signal; a) ANN construction and b) Schematic diagrams of the connection between input and output vectors for single neuron

where, $\mathrm{x}_{\mathrm{i}} \mathrm{w}_{\mathrm{i}}$ is a weighted input, $\mathrm{b}$ is the bias term which affects the output activation. Essentially each neuron includes an activation function $\mathrm{f}$ which is a mathematical equation that gives the output of processing neuron and prevents the output to reach an extreme amplitude. The activation functions of neuron are linear activation function, sigmoid function and tan sigmoid function. The experimental data includes crack position $\left(\mathrm{x}_{c} / \mathrm{L}\right)$ with range from (0.1-0.5), crack depth $d_{c} / d$ with range from $(0-0.9)$ for each crack position and natural frequency $\omega(\mathrm{rad} / \mathrm{sec})$. Training readings constitute $66 \%$ of the total reading, i.e., 33 reading. The remaining 17 readings were selected as 


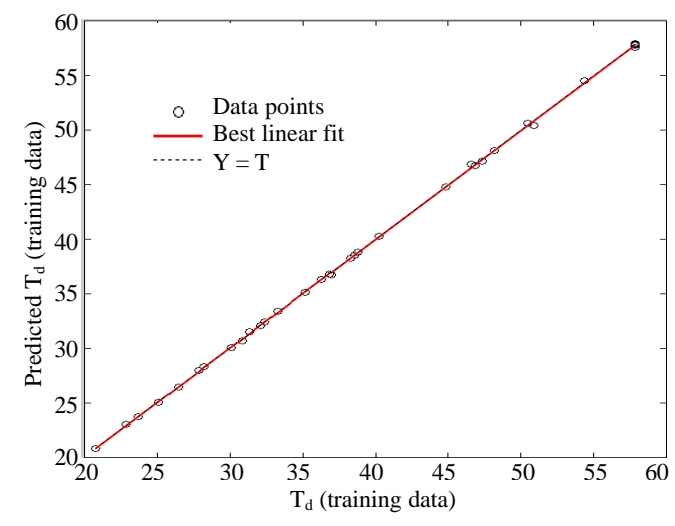

Fig. 7: Performance of prediction training data; Output vs. target, $\mathrm{R}=0.99992$

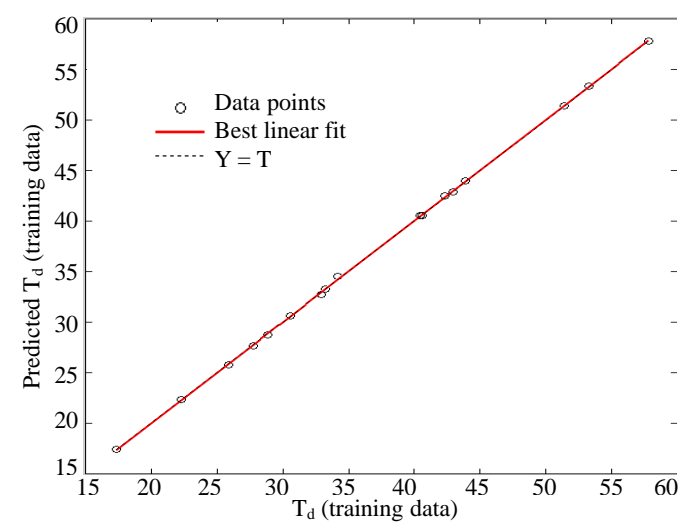

Fig. 8: Performance of prediction testing data; Output vs. target, $\mathrm{R}=0.99995$

test readings. For the purpose of obtaining higher accuracy, the test readings are chosen to be between the training readings.

In this research the two inputs of neural network are crack position $\left(\mathrm{x}_{c} / \mathrm{L}\right)$ and crack depth $\left(\mathrm{d}_{c} / \mathrm{d}\right)$ while there is one output of neural network natural frequency $\omega$ $(\mathrm{rad} / \mathrm{sec})$. After the necessary attempts of training of network reaching to high performance of neural network with a mean squared error (mse) is $4.3428 \mathrm{e}-5$, correlation factors for training and testing predicating data are 0.99992 and 0.99995 , respectively at 1000 epochs as shown in Fig. 7-9. The average of overall percentage errors between experimental and ANN results is $0.258 \%$.

Figure 5a shows the output signals of the accelerometer in time domain for the excited cable for defected and un defected cables for different crack size and position. Figure $5 \mathrm{~b}$ shows the output signal of FFT analyzer in frequency domain for evaluation of natural frequencies of defected and undefected cables for different size and position of the crack. It is clear from the

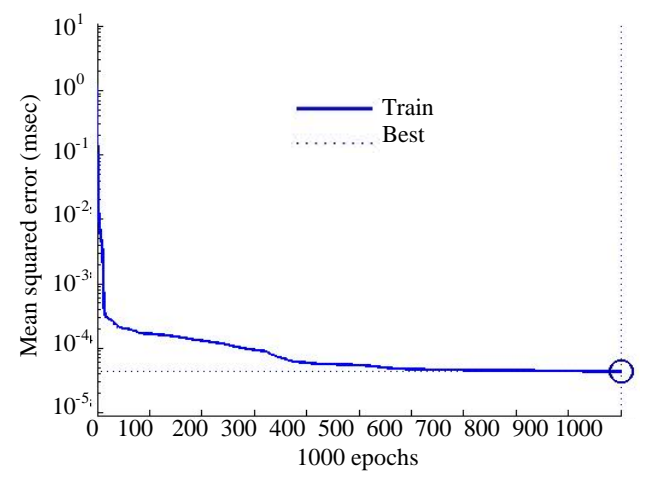

Fig. 9: Mean squared error with No. of epochs; Best training performance is $4.3428 \mathrm{e}-05$ at epoch 1000

results that the natural frequency of the cable varies with the variation of crack size and depth. FFT analyzer is fed to ANN system for predicting and determination of the size and position of the crack. Figure 7 and 8 show the training of the ANN system for the prediction and determination of the crack size and position. The output of the FFT analyzer is fed to ANN system for determination of the size and position of the crack.

\section{RESULTS AND DISCUSSION}

The results included evaluating the natural frequency of clamped cable with different crack depth and various crack position where by using these results for the crack size or position for cable by evaluated the value of natural frequency can be predicted. Then, by using ANN data (theory of neural network) the value of crack position or crack size can be evaluated by inputting the value of natural frequency. It is evaluated with experimental work or analytical solution. Therefore, the results show the relationship between natural frequency and crack size-position when the results are evaluated by using experimental work and analytical solution and then, comparing the experimental and analytical natural frequency results with ANN data (theory of neural network) agreement between the three techniques are found.

Figure 10-14 show the comparison of natural frequency results between experimental, analytical and ANN data technique for different crack depth $\left(\mathrm{d}_{\mathrm{d}} / \mathrm{d}=0.1-0.9\right)$ and various crack position $\left(\mathrm{x}_{\mathrm{d}} / \mathrm{L}=0.1-0.5\right)$. Figure 10-14 show that the results obtained by three techniques are in agreement with a maximum error between experimental work and ANN technique is $<1 \%$, also, the maximum error between experimental work and analytical technique are $<11.26 \%$. Therefore, form the results obtained from the experimental, analytical and ANN data (theory of neural network) technique are reliable to predict the crack size or position by measuring the natural frequency of cable. 


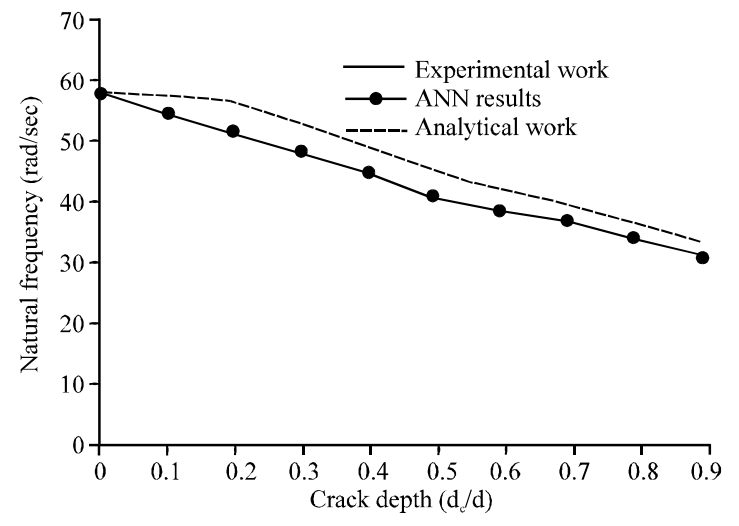

Fig. 10: Comparison between experimental, analytical and ANN data of natural frequency of the cable with different fault depth and fault position $\mathrm{x}_{c} / \mathrm{L}=0.1$

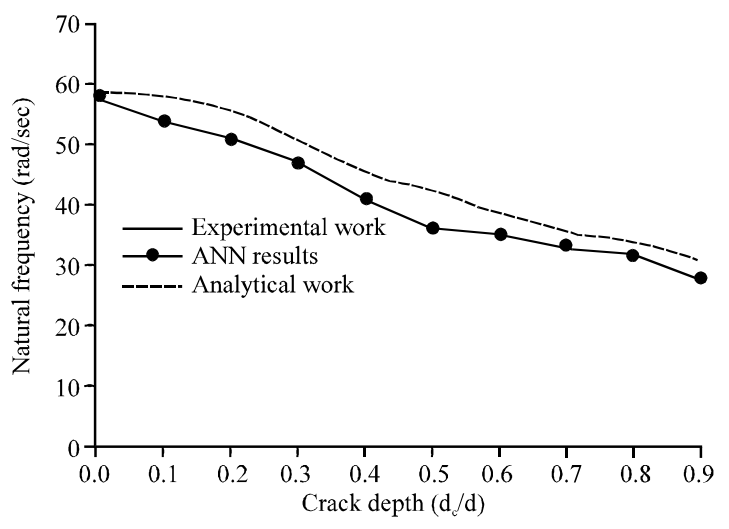

Fig. 11: Comparison between experimental and ANN data of natural frequency of the cable with different fault depth and fault position $x_{c} / L=0.2$

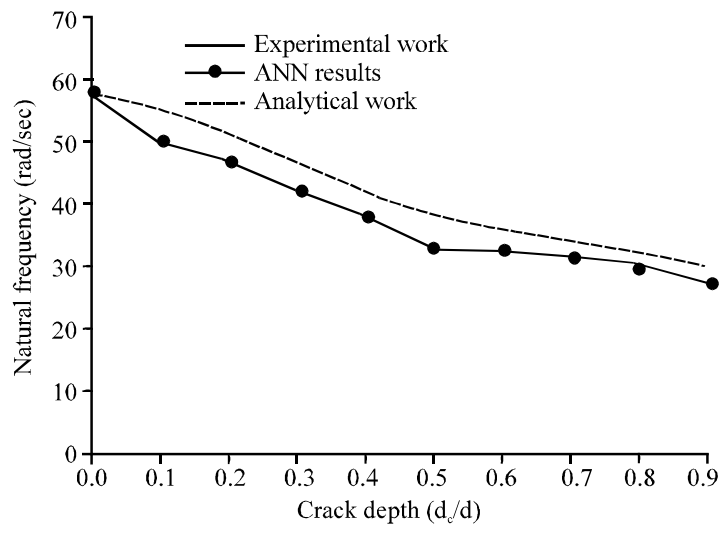

Fig. 12: Comparison between experimental and ANN data of natural frequency of the cable with different fault depth and fault position $\mathrm{x}_{c} / \mathrm{L}=0.3$

The effect of fault and location on the natural frequency evaluated by experimental test with different

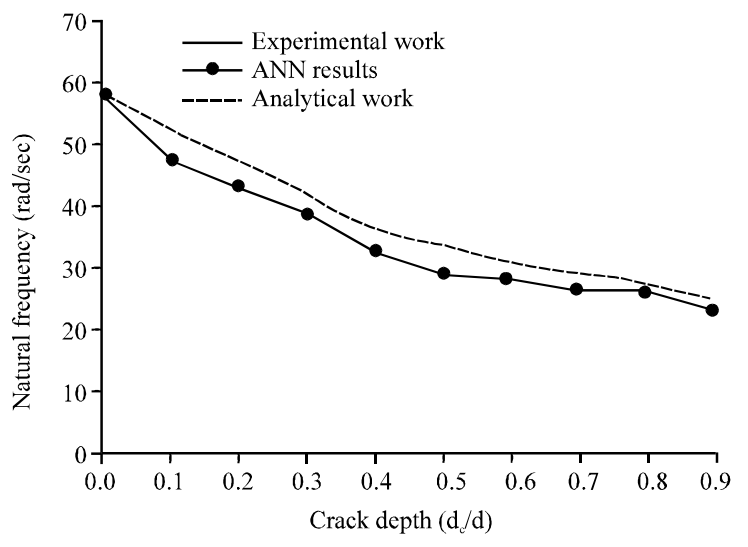

Fig. 13: Comparison between experimental and ANN data of natural frequency of the cable with different crack depth and crack position $\mathrm{x}_{c} / \mathrm{L}=0.4$

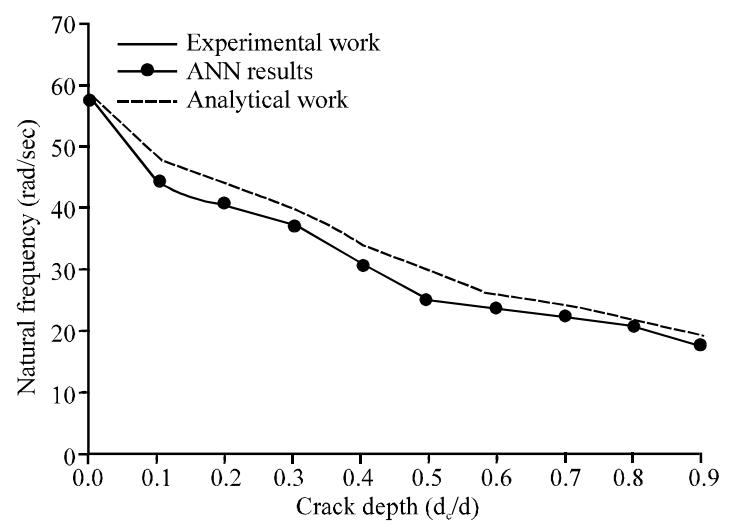

Fig. 14: Comparison between experimental and ANN data of natural frequency of the cable with different fault depth and fault position $\mathrm{x}_{c} / \mathrm{L}=0.5$

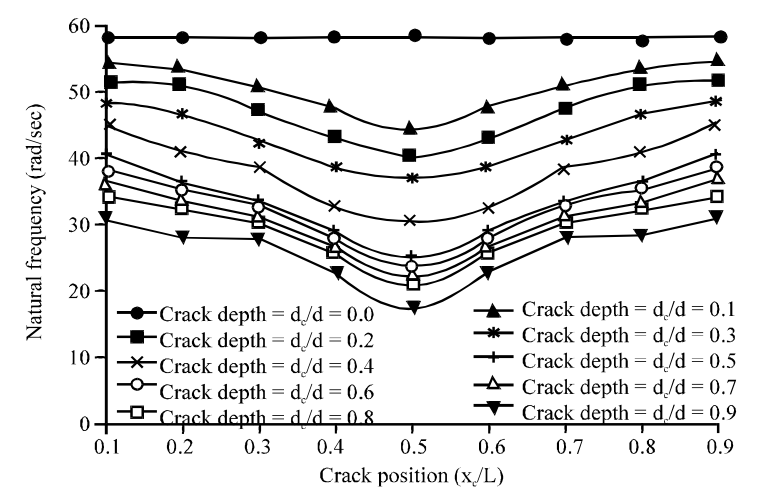

Fig. 15: Natural frequency of fixed cable with different fault position effects

crack depth and position are presented in Fig. 15 and 16. Figure show that the natural frequency decreases with increasing the size of crack, also, the natural frequency of cable with crack near to the ends is less than the natural 


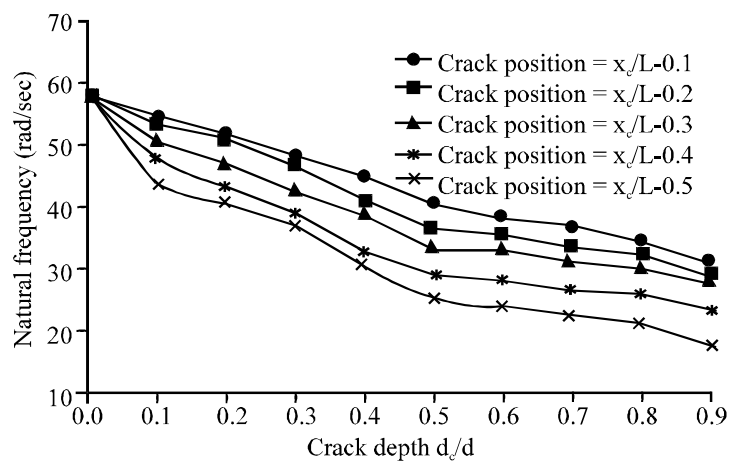

Fig. 16: Natural frequency of fixed cable with different fault depth effects

frequency of cable with crack near of the middle of the cable. The main causes to decrease the natural frequency is due to decrease of the stiffness of cable with increasing the size of the crack and being the effect of moment on the middle location of fixed cable more than the effect of moment on other location, then, the natural frequency decreases with crack location near the middle position.

The experimental results obtained from the tests of the cables included the evaluation of the natural frequencies for the clamped optical cable from both ends for defected and un-defected cables according to the variation of the position, type and depth of the defect, the measured natural frequency is changed. The experimental data obtained from the test of the optical cable for defected and undetected cable has been used as an input to ANN for the determination of the position and size of the crack in the fiber optical cable by using ANN technique.

\section{CONCLUSION}

This research presented the effect of crack characterization on the natural frequency of clamped cable. The crack size or position can be predicted by measuring the natural frequency of cable. From experimental and ANN data technique obtained in this research, the following points can be concluded:

The natural frequency of fiber optical cable varies with crack size and position obtained by experimental test. The ANN technique is used to predict the value of the natural frequency of the defected and undefected cables. It was found that the maximum percentage of error between the experimental and ANN technique results is $<1 \%$.

The ANN data is a good technique which can be used to predict the crack size and position depending on the measured natural frequency obtained experimentally for the defected cable.
The natural frequency of the cable decreases with increasing the crack size and the natural frequency of cable with fault position at the middle location of the cable and it is less than from the natural frequency of the cable with fault position at other locations.

\section{REFERENCES}

Abbas, H.J. and S.A.A. Taha, 2010. The optical fiber fault detection by computer simulation for OFDR system. Eng. Tech. J., 28: 5389-5403.

Al-Waily, M. and A.A. Deli, 2016. A suggested analytical solution of buckling investigation for beam with different crack depth and location effect. Int. J. Energy Environ., 7: 201-216.

Al-Waily, M., 2013. Experimental and numerical vibration study of woven reinforcement composite laminated plate with delamination effect. Intl. J. Mech. Eng., 2: $1-18$.

Al-Waily, M., 2015. A suggested analytical solution of oblique crack effect on the beam vibration. Int. J. Energy Environ., 6: 227-246.

Barnoski, M.K. and S.D. Personick, 1978. Mesurements in fiber optics. Proc. IEEE., 66: 429-441.

Dash, A.K., 2012. Multiple damage identification of beam structure using vibration analysis and artificial intelligence techniques. Ph.D Thesis, Department of Mechanical Engineering, National Institutes of Technology, Rourkela, Odisha.

Elkordy, M.F., K.C. Chang and G.C. Lee, 1993. Neural networks trained by analytically simulated damage states. J. Comput. Civ. Eng., 7: 130-145.

Gilgen, H.H., R.P. Novak, R.P. Salathe, W. Hodel and P. Beaud, 1989. Submillimeter optical reflectometry. J. Lightwave Technol., 7: 1225-1233.

Glombitza, U. and E. Brinkmeyer, 1993. Coherent frequency-domain reflectometry for characterization of single-mode integrated-optical waveguides. J. Lightwave Technol., 11: 1377-1384.

Hein, H. and L. Feklistova, 2011. Computationally efficient delamination detection in composite beams using Haar wavelets. Mech. Syst. Signal Proc., 25: 2257-2270.

Jweeg, M.J., 2016. A suggested analytical solution for vibration of honeycomb sandwich combined plate structures. Intl. J. Mech. Mechatronics Eng., 16: 9-17.

Jweeg, M.J., A.S. Hammood and M. Al-Waily, 2012. Experimental and theoretical studies of mechanical properties for reinforcement fiber types of composite materials. Int. J. Mech. Mech. Eng., 12: 62-75. 
Parhi, D.R. and H.C. Das, 2008. Smart crack detection of a beam using fuzzy logic controller. Intl. J. Comput. Intell. Theory Pract., 3: 9-21.

Parhi, D.R. and I.A. Khan, 2012. Fault detection in various structures using different methodologies: A review. Int1. Sci. Press, 4: 59-61.
Rao, S.S., 2011. Mechanical Vibration. 5th Edn., Prentice Hall, New Jersey, USA., ISBN:9780132128193, Pages: 1084.

Riveros, C.A., E.F. Garcia and M.A. Builes, 2010. A numerical approach for fault detection in beam-like structures using modal strain energy. Rev. EIA., 13: 171-184. 